\title{
Tree growth, recruitment, and survival in a tropical dry woodland: The importance of soil and functional identity of the neighbourhood
}

\author{
Jonathan Muledi $^{\mathrm{a}, 1}$, David Bauman ${ }^{\mathrm{b}, \mathrm{c}, 1}$, Arnaud Jacobs ${ }^{\mathrm{b}}$, Pierre Meerts ${ }^{\mathrm{b}}$, Mylor Shutcha ${ }^{\mathrm{a}}$, \\ Thomas Drouet ${ }^{\mathrm{b}, *}$ \\ ${ }^{a}$ Ecologie, Restauration Ecologique et Paysage, Faculté des Sciences Agronomiques, Université de Lubumbashi, Route Kasapa BP 1825, The Democratic Republic of the \\ Congo \\ ${ }^{\mathrm{b}}$ Laboratoire d'Écologie Végétale et Biogéochimie (EvB), CP244, Faculté des Sciences, Université Libre de Bruxelles, 50 av. F.D. Roosevelt, Brussels 1050, Belgium \\ ${ }^{\mathrm{c}}$ Environmental Change Institute, School of Geography and the Environment, University of Oxford, Oxford OX1 3QY, United Kingdom
}

\section{A R T I C L E I N F O}

\section{Keywords:}

Africa

Competition

Complementarity

Demographic rates

Forest

Functional traits

Miombo woodland

Neighbourhood effect

Soil

Vital rates

\begin{abstract}
A B S T R A C T
Understanding the processes that foster species coexistence is a longstanding goal in community ecology. Tradeoffs in species performances for different ecological functions have been proposed as a general mechanism of species assemblage. The nature of these trade-offs can be revealed by analysing the demographic characteristics of species combined with their functional traits (FT) and the surrounding environment.

The respective roles of soil, stand structure, and the functional dissimilarity of the neighbourhood, to the variations of growth, recruitment, and survival were determined for 19 most frequent tree species examined at the individual level in a tropical dry woodland (miombo; Democratic Republic of the Congo).

Four functional groups can be recognised by contrasting life-history strategies and mainly related to tree stature, leaf phenology, leaf area (LA), leaf nutrient content, ectomycorrhizal status, and dispersal mode. Growth is regulated by the functional dissimilarity of the neighbourhood, local stand structure, and soil conditions. Recruitment is comparatively less impacted by functional neighbourhood but is mainly influenced by stand basal area and mean DBH as well as available calcium. At the community level, survival is mainly explained by physical and chemical soil variables and by both negative and positive effects of traits dissimilarity with the neighbourhood.

Functional dissimilarity of the neighbourhood has the greatest positive effect on growth and survival, whereas competitive hierarchy is detrimental for growth of Caesalpinioideae species in particular, and for survival to a lesser extent.

The general involvement of foliar traits and stand basal area on demographic performances indicates that competition for light is a key axis of species niche differentiation along the fast-slow continuum, even in this tropical dry woodland. Our results also pointed out a trade-off between water resources and phosphorus availability or aluminium avoidance, which separates growth strategies and leads to habitat specialisation.

Multiple trade-offs allow species coexistence, with distinct drivers for tree growth, recruitment, and survival. Combining demographic and trait-based approaches provides unique key insights to understand species coexistence mechanisms.
\end{abstract}

\section{Introduction}

One of the main challenges of tree community ecology is to identify the drivers of species assemblage and elucidate the mechanisms of species coexistence (HilleRisLambers et al., 2012). Deterministic assembly processes predict habitat specialisation and the presence of trade-offs promoting species coexistence (Rees et al., 2001; Kneitel and
Chase, 2004). Variation of the abiotic environment is one factor allowing species coexistence at the local scale, each in its specialised habitat. But even in a near homogenous edaphic environment, species can coexist by partioning time or access to light (Barot and Gigoux, 2004), if they present differences in life history involving contrasting morphological, physiological or phenological trait values. Opposing strategies among species leading to niche complementarity can also be

\footnotetext{
* Corresponding author.

E-mail address: Thomas.Drouet@ulb.ac.be (T. Drouet).

${ }^{1}$ Equally contributing authors.
} 
observed in their demographic characteristics: growth, recruitment, and mortality rates. As one species cannot simultaneously maximally allocate its resources to the different physiological functions and anatomical characteristics related to the different components of its fitness (i.e. growth, survival, reproduction), life history differences and demographic trade-offs can emerge (Lusk and Smith, 1998; Easdale et al., 2007; Russo et al., 2008). The growth-survival trade-off is often mentioned as a mechanism of coexistence in forest ecosystems (Sterck et al., 2006; Wright et al., 2010; Adler et al., 2014). However, examining the variation of demographic rates using a global tropical forest dataset, Condit et al. (2006) showed that the most diverse forests had the least demographic variation and that this trade-off was clearly not sufficient to explain coexistence in those ecosystems. More accurate knowledge is therefore needed to understand the interplay between species coexistence, demographic rates, and functional characteristics.

Assembly mechanisms and species coexistence are generally analysed through the lens of species abundance data (e.g., Vleminckx et al., 2015, 2017; Muledi et al., 2017). However, this approach can be inaccurate when the system is not at equilibrium or when local exclusion is not reached (Schurr et al., 2012). Moreover, the static view of species abundance in a community is unable to assess past environmental conditions or recent disturbance unequivocally (Blonder et al., 2017). Other processes like limited dispersal can also confine recruits to suboptimal habitats (Ozinga et al., 2005; Pinto and MacDougall, 2010) whereas source-sink dynamics through the mass effect induced by high rates of regional dispersal can upset local community abundances (Lasky et al., 2013). These different influences can be better detected via measures of tree growth rates and/or from recruitment and survival data which involve measurements at several time steps. Demographic rates, unlike species abundances, are direct measurements of the species fitness (Laughlin et al., 2018; Salguero-Gómez et al., 2018), and can therefore, offer a more relevant insight into the drivers of the community assembly (HilleRisLambers et al., 2012; Bin et al., 2016; Salguero-Gómez et al., 2018, for a review).

Tree demographic rates (equally referred to as 'vital rates') first depend on the species' own life history strategy (Swaine et al., 1990; Lusk and Smith, 1998; Gourlet-Fleury and Houllier, 2000; Adler et al., 2014; Pausas and Keeley, 2014). Many authors have attempted to classify groups of species based on their life history characteristics (Franco and Silvertown, 1996; Adler et al., 2014; Salguero-Gómez, 2017). In forests, life history strategies can be described by the forest layer type (e.g. understorey, canopy or emergent, Rüger et al., 2018), by the successional status (e.g. pioneer, secondary, late; Swaine and Whitmore, 1988), but also by light-demanding guilds separated by different light requirements (e.g., shade tolerant, mid-tolerant, long- or short-lived light-demanding; Vleminckx et al., 2014). Other authors have chosen to separate the tree community directly based on the vital rates (Gourlet-Fleury et al., 2005; Mugasha et al., 2016), but a classification encompassing both traits and demographic performances remains a delicate task (Salguero-Gómez et al., 2018).

A fair view of the effects of life history strategies on the demographic rates of a community is provided by the analysis of functional traits (FT) (Adler et al., 2014; Salguero-Gómez, 2017). Different authors have indeed highlighted the value of functional traits related to the different components of fitness to explain and predict varying vital rates in different types of ecosystems (e.g., Poorter and Bongers, 2006; Hérault et al., 2011; Wigley et al., 2016; Laughlin et al., 2018). Indeed, the functional nature of a trait in a given environment and community assemblage can only be confirmed through the effect it has on species' fitness or its components (i.e., vital rates) (Violle et al., 2007; Laughlin et al., 2018). Moreover, the sole use of trait-environments relationships can be ambiguous and has recently been shown to sometimes poorly correlate with the functional nature of traits highlighted by their effects on vital rates (Laughlin et al., 2018). Demographic approaches of community ecology also benefit from using traits, as their combination can provide deeper insights into the mechanisms through which vital rates are affected (Salguero-Gómez et al., 2018). In addition, combinations of certain traits have been shown to reflect different demographic trade-offs, such as the fast-slow continuum (Reich, 2014; PradoJunior et al., 2016), the growth-survival trade-off related to reproduction strategies (Salguero-Gómez, 2017), or the 'stature-recruitment' trade-off which highlights the relationships between regeneration functional traits (e.g. seed mass, dispersal mode) and recruitment (Rüger et al., 2018).

The resulting trade-offs among demographic rates constrain the range of viable life history strategies in a given environment. Since the multi-dimensional niche of species consists of several independent axes of resources (Kneitel and Chase, 2004; Hérault et al., 2011), and because the relative importance of these axes is context-specific and often non-generalisable (HilleRisLambers et al., 2012; Wigley et al., 2016), the study of specific communities is necessary to detect and understand original combinations of functional trade-offs related to the local environmental constraints.

Soil potentially also has a large effect on demographic performances. Nutrient supply and soil water availability may influence spatial and temporal patterns of growth (Baker et al., 2002, 2003a). This has been shown at regional (Baker et al., 2003b; Quesada et al., 2009) and local scales (Baker et al., 2003b; Russo et al., 2005). In addition, the dynamics of functional groups have been shown to respond differently to soil resources, which are important factors of niche differentiation (e.g. Russo et al., 2005; Kariuki et al., 2006; BrenesArguedas et al., 2008).

Finally, an increasing number of studies has emphasised the effect of the neighbourhood on the demographic rates of trees, be it for growth (Sánchez-Gómez et al., 2008; Uriarte et al., 2010), recruitment (Brown and Karubian, 2016), or survival (Olano et al., 2009; Wang et al., 2012). We focused on negative effects of neighbouring trees on individual performances, as a result of competition for shared resources or through common natural enemies, that is, two crucial mechanisms for tropical forest dynamics (e.g. Comita et al., 2009; Fortunel et al., 2016). Such negative effect is commonly observed in the context of competition for light, which increases with stand density (SánchezGómez et al., 2008). A negative effect of the neighbourhood on a focal tree can however be related either to high or to a low functional similarity. First, negative interactions with neighbourhood may reflect the relative position of species on a hierarchy of competitive ability (Kunstler et al., 2012; Fortunel et al., 2016). In this case, it is the absolute value of traits which matters and places the different species higher or lower on the competitive ability scale, given the local environmental conditions (Kunstler et al., 2012; Fortunel et al., 2016). In parallel, neighbourhood negative effects on individual performances can also be related to limiting similarity, with functionally similar neighbourhood decreasing individual performances. Indeed, the effect of competition or natural enemies within a species or among species with similar trait values is generally larger - providing that traits are good predictors of resource use and defences against enemies - and has been shown to affect individual performances (Adler et al., 2014; Ledo, 2015; Fortunel et al., 2016; Chen et al., 2016; Zambrano et al., 2017; Grossman et al., 2017). Trees often grow faster, recruit more, and survive better when surrounded by more dissimilar neighbours (Brown and Karubian, 2016). This can be interpreted as a result of a release of the intraspecific competition through the mechanisms of limiting similarity or negative density dependence (natural enemies, JanzenConnell effect) (Agrawal and Fishbein, 2006; Chen et al., 2018). It can also be the consequence of real neighbourhood complementarity (Sapijanskas et al., 2014; Chen et al., 2016).

In this study, we investigate the drivers of the vital rates of a tropical dry woodland in southern Africa to uncover the mechanisms of tree species coexistence. Tropical dry woodlands of the Zambezian region (generally referred to as miombo woodlands) have been poorly studied compared to other tropical forests. The miombo woodland is characterised by a marked seasonal drought and frequent disturbances 
(wildfire) (Frost, 1996). In miombo woodlands, constraints on growth, recruitment, and mortality are poorly understood, and plant life history strategies remain little known.

Here, we investigate the influence of fine-scale soil physico-chemical heterogeneity, stand structure features, and functional composition of neighbourhood on individual tree demographic performances in a wet miombo woodland. To do so, we report a 4-year interval census of tree growth, stem recruitment, and survival from a 10-ha forest dynamics plot located in a miombo woodland near Lubumbashi, DRC (Muledi et al., 2017, 2018). This dataset encompasses an unprecedentedly large number of species of the wet miombo and was used to determine the main factors controlling demographic rates in this environment. The following specific questions are addressed on the basis of generalised linear (mixed) models at the individual level:

(1) Are the drivers of tree demographic performance identical for growth, recruitment, and survival? (2) What is the relative importance among the influence of soil variables, stand structure, and neighbourhood effects (i.e. local functional dissimilarity) on demographic rates? (3) Can we observe classical demographic trade-offs (growth-survival, recruitment-adult growth, recruitment-survival, adult stature-recruitment) in this community?

Tree species of the miombo present a high diversity in wood density and leaf phenology (presence of evergreen, semi-evergreen and deciduous species). This suggests a separation between fast-growing acquisitive pioneer and slow-growing conservative species (Reich, 2014; Méndez-Alonzo et al., 2012). Based upon the results of two previous studies on the same site describing species-habitat associations (Muledi et al., 2017) and ectomycorrhizal-host relations to the environment (Bauman et al., 2016), we hypothesized that the fast-slow continuum will manifest following three axes of resources limitations: the classical light gradient, but also the water and nutrient availability. We expected that (1) soil heterogeneity explains a large part of growth differences among species, in particular water retention capacity (low gravel loads, high clay content), P availability and Al toxicity; (2) traits linked to resource conservation syndrome, (high values for LDMC, WD, seed mass, low values for LA, SLA), or to the access to supplementary resource pools via ectomycorrhizae, will be fostered by higher demographic performance in this environment experiencing long drought period, element deficiencies or toxicity.

\section{Materials and methods}

\subsection{Study site}

This research was carried out in the Mikembo Natural Reserve, a 530-ha miombo woodland located ca. $35 \mathrm{~km} \mathrm{NE}$ of Lubumbashi, Upper Katanga, DR Congo. In 2009, a permanent plot of 10 ha $(200 \times 500 \mathrm{~m}$; 160 quadrats of $25 \times 25 \mathrm{~m}$ each) was installed $\left(11^{\circ} 28^{\prime} 57^{\prime \prime}\right.$ to $11^{\circ} 29^{\prime} 05^{\prime \prime} \mathrm{S}, 27^{\circ} 40^{\prime} 12^{\prime \prime}$ to $27^{\circ} 40^{\prime} 28^{\prime \prime} \mathrm{E} ; 1220 \mathrm{~m}$ a.s.l.) (Muledi et al., $2017,2018)$. The climate is Sudanian with mean annual temperature of $20.5^{\circ} \mathrm{C}$, mean annual rainfall of $1239 \mathrm{~mm}$, and six months of dry season from May to October (Schmitz, 1971). Geological substrate consists of dolomitic shales and siltstones from Neoproterozoic Nguba and Roan Groups (Batumike et al., 2006). The flat topography of the site is regularly punctuated by termite mounds up to $8 \mathrm{~m}$ high. Soils are characterised by low $\mathrm{pH}$ and nutrient content and a textural gradient associated to higher $\mathrm{P}$ and lower $\mathrm{Al}$ contents (coarse sandy loam, west side) or higher water availability and nutrient content (clay and sandy clay, east side) (Muledi et al., 2017). The vegetation is typical miombo woodland of the wet type, with Julbernardia paniculata, Diplorhynchus condylocarpon, and Marquesia macroura as most frequent species. Tree species exhibit large differences in leaf structure and phenology, wood density, and ectomycorrhization status (Bauman et al., 2016). The site has been protected from fire and fuel-wood cutting since 2003. Before this date, this woodland has been subjected to fire and, at least in part, to slash and burn cultivation. Traces of human disturbance such as cultivation ridges and charcoal were observed in the eastern portion of the plot with higher clay content and lower gravel load, probably because of easier soil tillage conditions (Muledi et al., 2017). From the age-diameter relationships presented in Schmitz (1971) for several species in the same region, we estimated the oldest tree of the plot being over 100 years old.

The 10-ha plot was systematically inventoried for all living and dead trees $\geq 10 \mathrm{~cm}$ DBH (diameter at breast height at $130 \mathrm{~cm}$ ). Trees were tagged, mapped, identified to the species level, and measured for DBH in 2010 and 2014, at the beginning of the dry season. The plot comprises thirty-three termite mounds (Macrotermes sp.) covering 5\% of the plot area. Termite mound soil has particular chemical and physical properties, and, termite mounds host tree communities that are completely distinct from the surrounding matrix (Cuma Mushagalusa et al., 2018); therefore, termite mounds were not included in this study.

\subsection{Demographic performances}

Basal area increment (BAI, $\mathrm{cm}^{2} \mathrm{y}^{-1}$ ) was chosen as representative of tree growth. It was correlated $(r=0.72)$ with the mean diameter increment (MDI, $\left.\mathrm{cm} \mathrm{y}{ }^{-1}\right)$. BAI was calculated as BAI $=\pi\left(\mathrm{DBH}_{1}{ }^{2}\right.$ $\left.\mathrm{DBH}_{0}^{2}\right) / 4$, where $\mathrm{DBH}_{1}$ and $\mathrm{DBH}_{0}$ are diameter at breast height in the 2014 and 2010 censuses, respectively. Negative diameters increments were observed for a few individuals. None of these values exceeded or even approached the threshold of $-0.4 \mathrm{~cm} / \mathrm{y}$ proposed by Baker et al. (2002) separating natural variation and measurement errors. Therefore, these negative values were interpreted as stem shrinkage during the dry season and were retained in the dataset. They were no cases of individuals with growth rates more than 4 standard deviations from the mean, considered as measurement errors (Rüger et al., 2011). BAI was used as the response variable in linear models built to model individual growth (see Section 2.6, below). The response variables used for stem recruitment and mortality were simple vectors of 1 and 0 , as we modelled these variables using logistic regressions (see Section 2.6, below).

We also computed the relative population stem recruitment and mortality rates of each tree species in order to include them as explanatory variables in the linear models of the growth, recruitment, and mortality response variables already described (for the analyses of the whole community only; see Section 2.6 ). The relative population stem recruitment was calculated for a given species as Recr. rate $=(\ln$ $\left.N_{1}-\ln S\right) / t$, where $N_{1}$ is the number of living stems at the second census in 2014, $S$ is the number of survivors for the target species in 2014 and $t$ is the time interval between census years, (ln) is the natural logarithm. Stem mortality rate was measured for each species as Mort. rate $=\left(\ln N_{O}-\ln S\right) / t$, where $N_{o}$ is the number of living trees in 2010, $S$ is the number of survivors (number of stems present in 2010 that are still alive in 2014) and $t$ is the time interval between these two measurements (Condit et al., 1999). The plot-specific species mean growth rate (BAI) was also used as explanatory variable for the communitylevel models of recruitment and mortality, to assess demographic tradeoffs based on a local measurement of growth.

\subsection{Soil analyses}

Soil variables were measured on five bulked $0-20 \mathrm{~cm}$ depth soil cores collected in each quadrat of $25 \times 25 \mathrm{~m}$. Sixteen edaphic variables were selected to reflect the soil physical and chemical variability of the site, i.e. soil clay content (\%Clay), soil depth (Depth), bulk density (BD), gravel load (GL), $\mathrm{pH}$ in water $\left(\mathrm{pH}-\mathrm{H}_{2} \mathrm{O}\right)$, organic matter content $(\mathrm{OM})$, carbon on nitrogen mass ratio $\left(\mathrm{C} / \mathrm{N}\right.$ ratio), the $\mathrm{Al}$ saturation rate $\left(\mathrm{Al}_{\mathrm{Sat}}\right)$, concentrations in plant-available forms of elements $(\mathrm{Ca}, \mathrm{Mg}, \mathrm{K}, \mathrm{Al}, \mathrm{Fe}$, $\mathrm{Mn})_{\mathrm{Av}}$. Protocols of soil analyses are given in Bauman et al. (2016) and Muledi et al. (2017). Two forms of soil phosphorus were determined with Olsen method $\left(\mathrm{P}_{\text {Olsen }}\right)$ and $\mathrm{NH}_{4}$-Acetate-EDTA extraction $\left(\mathrm{P}_{\mathrm{EDTA}}\right)$. 


\subsection{Functional traits}

All traits were measured following the protocols of PérezHarguindeguy et al. (2016). Eleven functional traits were considered in this analysis by averaging 10 individuals for each species and each trait: maximum tree height $\left(\mathrm{H}_{\text {max }}, \mathrm{m}\right)$, leaf area (LA, $\left.\mathrm{cm}^{2}\right)$, specific leaf area (SLA, $\mathrm{cm}^{2} \mathrm{~g}^{-1}$ ), leaf dry matter content (LDMC, $\mathrm{mg} \mathrm{g}^{-1}$ ), the degree of deciduousness (Deci), leaf nitrogen concentration ( $\mathrm{LN}, \mu \mathrm{g} \mathrm{g} \mathrm{g}^{-1}$ ), leaf phosphorus concentration (LP, $\mu \mathrm{g} \mathrm{g}^{-1}$ ), wood density (WD, $\mathrm{g} \mathrm{cm}^{-3}$ ), seed dry mass (SM, mg), root ectomycorrhization status (Ecto, binary) and fire tolerance (FTol). $\mathrm{H}_{\max }$ could not be calculated in a regular way because only the $10 \%$ highest trees were measured for height in each $50 \times 50$ quadrat. However these truncated values were correlated (Pearson $r=0.69$ ) with $\mathrm{D}_{\max }$ corresponding to the $95 \%$ distribution of all tree diameters of each $25 \times 25$ quadrat. Ectomycorrhization status was obtained from Bâ et al. (2011) and checked in another study on the site (Bauman et al., 2016). For leaf phenology, three categories were recognized, and used to define a deciduousness variable with the following values: 0 (evergreen), 0.5 (semi-evergreen: leaves shed $<30$ days before budbreak), and 1 (deciduous: leafless for more than 30 days in the dry season). Fire tolerance index (FTol) was derived from Trapnell (1959), Lawton (1978) and Cauldwell and Zieger (2000) and comprised three categories: 0 (not tolerant), 0.5 (semi-tolerant), 1 (tolerant). Four missing values for fire tolerance were obtained using a Bayesian Hierarchical Matrix Factorization gap-filling method (Schrodt et al., 2015), taking other traits and taxonomy into account. For each functional trait, we quantified the functional dissimilarity of each individual tree relative to its neighbourhood (i.e. $25 \times 25 \mathrm{~m}$ quadrat) through a functional distance index (FD). The FD for trait $T$ was calculated as: $T_{\mathrm{FD}}=\sum_{i=1}^{n}\left(F_{\text {ind }}-F_{i}\right) / n$, where $F_{\text {ind }}$ and $F_{i}$ are the trait value of the focal individual and neighbour $i$, respectively, and $n$ is the total number of neighbours in the quadrat. The resulting predictor variables $\left(\mathrm{H}_{\max }, \mathrm{LA}, \mathrm{SLA}, \mathrm{LDMC}\right.$, Deci, $\mathrm{LN}, \mathrm{LP}, \mathrm{WD}, \mathrm{SM}$, Ecto, and $\mathrm{FTol})_{\mathrm{FD}}$ represent the functional dissimilarity of the neighbouring individuals. A positive relationship between individual performances and FD was interpreted as the sign of a limiting similarity mechanism, whereas a negative relationship between individual performances and FD was considered as the sign of a competitive hierarchy mechanism. Six other functional traits were included in Table S2 to describe species and functional groups: life form (micro- or mesophanerophyte) and dispersal mode (auto, autochorous; anemo, anemochorous; zoo, zoochorous) (Meerts, 2016; White, 1962), leaf C/N ratio (LCN), leaf N/P ratio (LNP), and leaf lignin content (Lign, \%) (Bauman et al., 2016), as well as maximum tree diameter $\left(\mathrm{DBH}_{\max }\right)$ (this study).

\subsection{Stand structure and characteristics}

Three structural attributes and characteristics of the stand were calculated for each quadrat: basal area $\left(\mathrm{m}^{2} \mathrm{ha}^{-1}\right)$, mean DBH $(\mathrm{cm})$, and mean relative DBH (without units). Quadrat basal area $\left(\mathrm{m}^{2} \mathrm{ha}^{-1}\right)$ is a classical index to reflect the general intensity of competition (Biging and Dobbertin, 1995). Mean DBH was interpreted as a proxy for the natural or anthropogenic disturbance regime, reflecting the successional stage of the community in the quadrat.

\subsection{Statistical treatments}

The analyses were performed at the species-level, at the communitylevel, and with respect to the functional groups highlighted in a separate analysis.

\subsubsection{Species-level analyses}

The analyses of growth, recruitment, and survival were performed on the individual data. All predictor variables were Box-Cox transformed to linearise relationships and stabilise variances, with the exception of binary variables and mortality rates which present many null values. Nineteen species present in a minimum of 50 quadrats were selected for separated analyses at the species level. The same species were also analysed altogether, in what we will refer to as a community-level analysis. Inside each quadrat, the percentage of the total stem number from the target species was $91.5 \pm 7.4 \%$, which is more than the minimum of $80 \%$ of species representation prescribed by Pakeman and Quested (2007) for trait analyses. Initial tree size expressed as DBH, soil variables, stand structural attributes as well as neighbouring functional environment (FD) in the corresponding quadrat of the focal individual were chosen as predictors of tree growth, stem recruitment, and survival.

A preselection of predictor variables was conducted to avoid multicollinearity (Dormann et al., 2013) (see Appendix S1 - Section 1 for details). This preselection consisted in computing all the pairwise Pearson's correlations between explanatory variables and to remove one of the variables of all the pairs displaying an absolute correlation value higher than 0.7 (see Table S1). Some variables were therefore excluded for the benefit of their correlated counterpart and might not be ignored during the interpretation of the results for a complete view on the explanatory variables.

All variables were standardised to have zero mean and unit standard deviation, which facilitated the interpretation and allowed the ranking of the effects through the importance value (Comita et al., 2009). For each species, we determined the limiting sample size on the basis of a minimum of 10 observations per predictor variable, and in all cases limited the maximum number of predictors to 10 , for the sake of parsimony. Generalised linear models were used to infer the determinants of tree demographic rates at the specific and at the community level. Multiple linear regressions were applied to describe tree growth for each species separately, with the following model: $\mathrm{BAI}=\beta_{0}+\beta_{1} \mathrm{x}_{1}+\cdots+\beta_{\mathrm{n}} \mathrm{x}_{\mathrm{n}}$, where $\beta_{0} \cdots \beta_{\mathrm{n}}$ are regression coefficients and $\mathrm{x}_{1}, \mathrm{x}_{2} \cdots \mathrm{x}_{\mathrm{n}}$, are explanatory variables. Multiple logistic regressions were used in combination with the logit link function to model the probability of tree recruitment (Pr) and survival (Ps). The binary variable (recruit/adult) or (dead/alive) were constructed using the logistic model: Logit (Pr) or (Ps) $=\beta_{0}+\beta_{1} x_{1}+\cdots+\beta_{n} x_{n}$, where $\operatorname{Pr}$ and Ps are probability of recruitment and survival, respectively.

We applied a corrected AIC-based model selection approach (Burnham and Anderson, 2002) provided by the glmulti package (Calcagno and de Mazancourt, 2010) which allows us to assess modelselection uncertainty and to perform multi-model inference. In order to bypass an exhaustive analysis of all variable combinations, we used a genetic algorithm method which only explored an optimised subset of all possible models (Calcagno and de Mazancourt, 2010). We made a consensus of 10 simulations of the genetic algorithm to improve convergence and to avoid local optimum issues. A model averaging was performed to estimate coefficients and variability by taking the first 50 best-ranking models into account, weighted by the Akaike Information Criterion value corrected for small samples $\left(\mathrm{AIC}_{\mathrm{c}}\right)$.

The presence of a significant spatial autocorrelation in the residuals of all 50 best-ranking models was assessed and explicitly taken into account when present, using Moran's eigenvector maps (MEM; Dray et al., 2006). This was done following the recommendations of Bauman et al. (2018a,b), in the adespatial package (Dray et al., 2019), to select both the spatial weighting matrix and a subset of spatial predictors, hence optimising the detection of any spatial structure in the model residuals using a minimum number of spatial predictors in an accurate and unbiased way (details in Appendix S1). Whenever a significant spatial autocorrelation was detected in model residuals, the predictor coefficients of the corresponding model were re-estimated after inclusion of the optimised selected subset of MEM variables in order to yield unbiased estimates. We then retained predictor variables with importance value $\geq 0.7$ for inference. We used the unconditional coefficient estimates of the averaged model to evaluate the intensity and the sign of the effect of each retained predictor.

For logistic regressions, the retained explanatory variables and averaged coefficients were included in a reduced model and we assessed the predictive ability of the global and the reduced models. The predictive ability of the logistic models was assessed by plotting the 


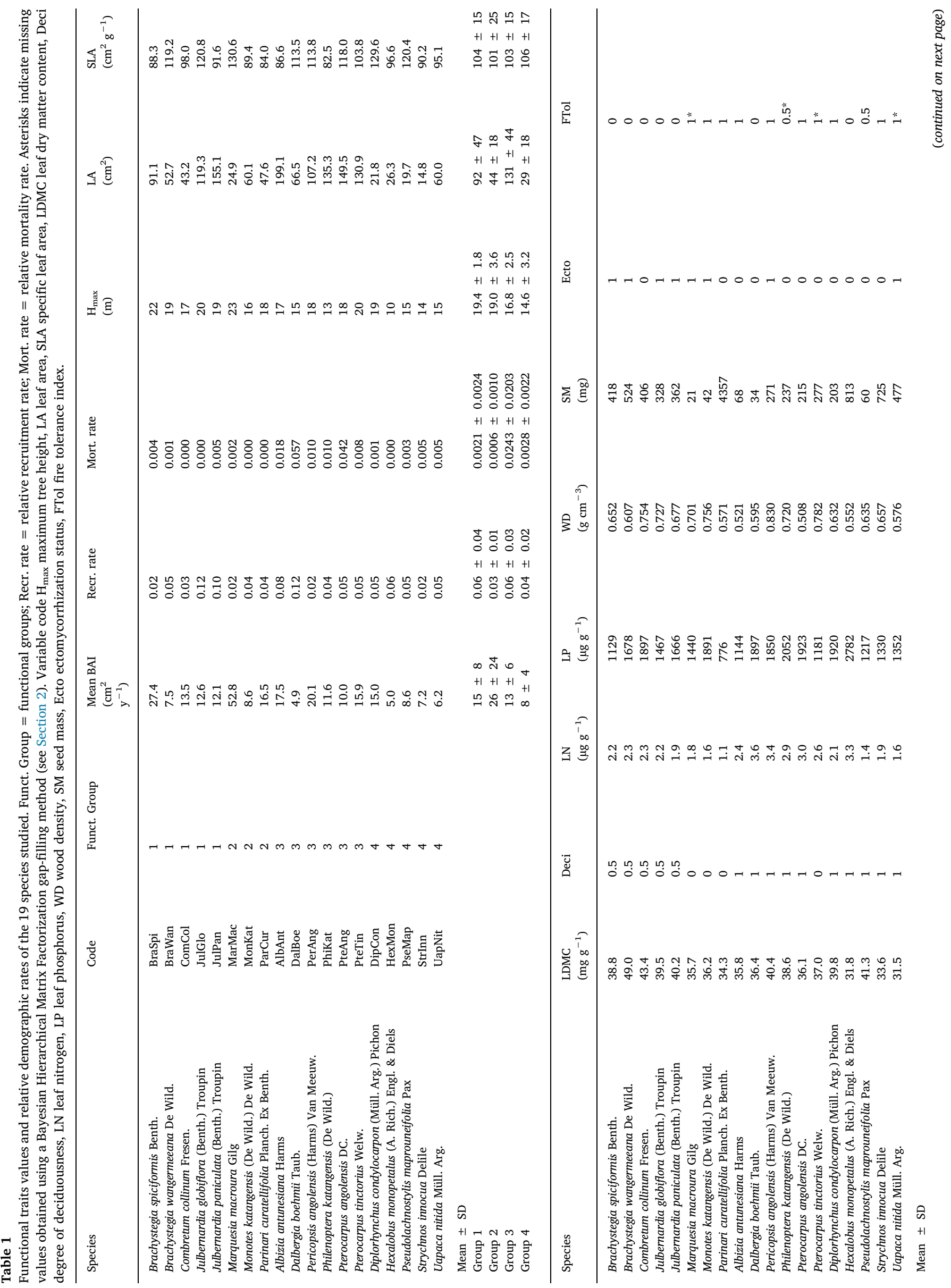


ROC curve (Receiver Operating System) of a graph of true positive rate against false positive rate constructed with an independent subset of $10 \%$ of the whole dataset (10-fold cross validation). Then the area under this curve (AUC) was determined, and yielded mean scores of 0.68 and 0.61 for recruitment and survival, respectively. Sensitivity and specificity at the optimal cut point of this curve (where the sum of sensitivity and specificity is maximal) was assessed with the 'ROC' function of the Epi package (Carstensen et al., 2018). Internal and crossvalidation (10-fold) estimates of accuracy were determined using the 'CV.binary' function from the DAAG package (Maindonald and Braun, 2010). The McFadden's pseudo- $r^{2}$ of the mortality and recruitment reduced models were on average 0.04 and 0.02 , respectively (a value of 0.2 is considered high for such analyses) (McFadden, 1974). Indicators of the predictive capacity of all logistic models (pseudo- ${ }^{2}$, sensitivity and specificity of the optimal cut point, AUC and others) can be found in Table S5.

\subsubsection{Community-level analyses}

At the community level, a corresponding (i.e. either Gaussian or binomial) mixed model was used, by adding a random intercept for species identity to the models described in the previous section, and by allowing it to have random slopes with respect to the initial $\mathrm{DBH}$, as ontogenetic influences on growth, survival, and recruitment can strongly differ among tree species. These generalised linear mixed models (GLMM) have the advantage of estimating all species' coefficients simultaneously while learning from these to estimate the coefficients for the unknown population of species (from which our species were theoretically sampled). We refer to these latter coefficients as community-level coefficients. Unlike the species-level analyses, focusing on the coefficients of the community-level approach will allow us to explore community-level trends with respect to soil, stand structure, and the functional composition of tree neighbourhood.

\subsubsection{Functional group-level analyses}

We used a Principal Coordinate Analysis (PCoA) with 17 quantitative and qualitative trait data (see Table 1) and Gower dissimilarity index (Laliberté and Legendre, 2010) to identify the potential axes of niche differentiation, followed by a Ward clustering (Legendre and Legendre, 2012) to separate tree species in functional groups.

The community-level approach described above was then used separately for the species of each functional group. The GLMM performed at the functional group level aim to highlight particular relationships with and trade-offs with respect to the functional neighbourhood of trees, their soil conditions and local stand structure. These analyses will also test whether the functional groups suggested by descriptive ordination and clustering methods are ecologically sound and confirm the demographic and functional trade-offs (see Introduction).

All statistical treatments were carried out using the statistical computing program $\mathrm{R}$, version 3.6.0 ( $\mathrm{R}$ Development Core Team, 2018).

\section{Results}

\subsection{Functional groups and demography}

In 2010, the 10-ha plot comprised a total of 3118 stems (DBH $>10 \mathrm{~cm}$ ), corresponding to 85 species, 58 genera and 33 families. The total number of stems increased to 3902 in the second census in 2014. The five most frequent species in the site were Julbernardia paniculata (26.9\%), Diplorhynchus condylocarpon (9.3\%), Marquesia macroura (6.5\%), Brachystegia wangermeeana (6.6\%), and Julbernardia globiflora (5.5\%) (Table S6). The PCoA allowed separating the community into four groups on the basis of their FT (Fig. 1 and Table S4). This highlighted three main axes of niche differentiation: 1) $\mathrm{H}_{\text {max }}$, Ecto, Deci, LDMC, dispersal mode (zoo, auto) and life form (micro, meso), correlated to the first component 2) FTol, evergreeness, 

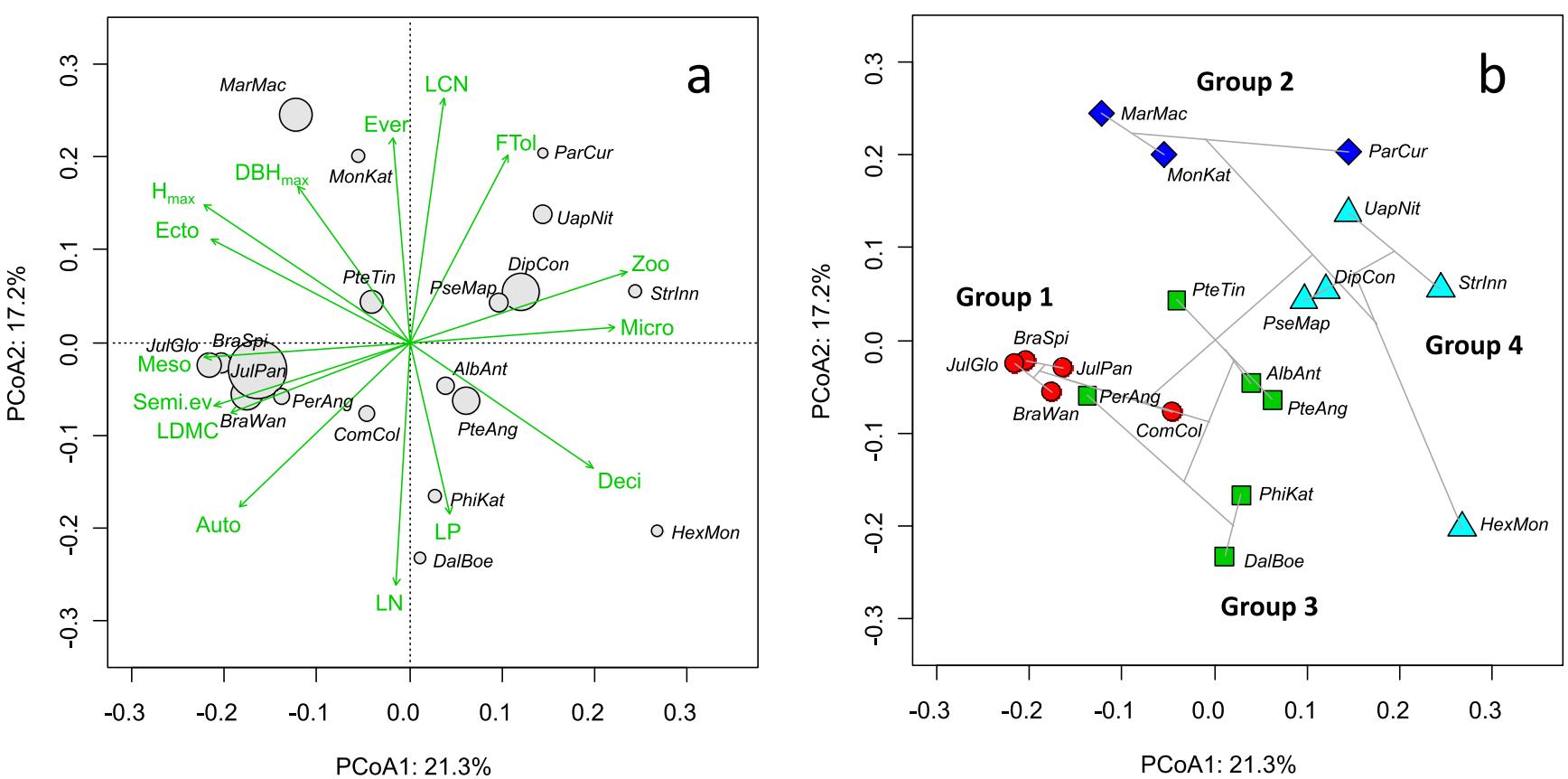

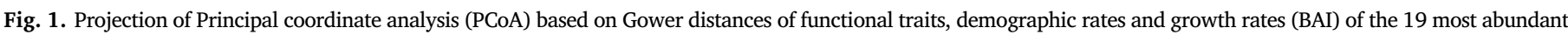

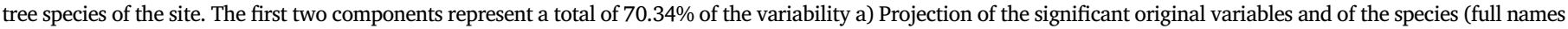

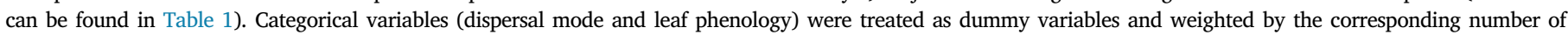

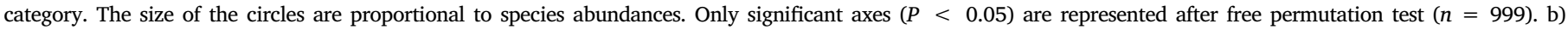

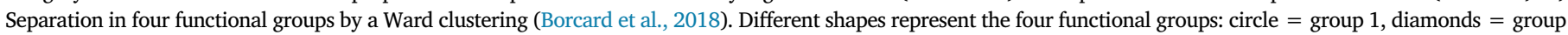

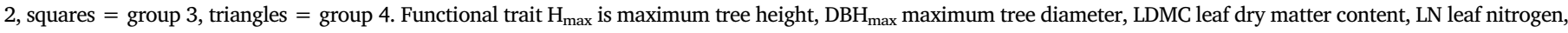

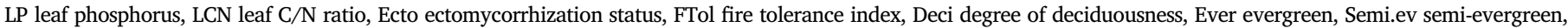
Meso mesophanerophyte, Micro microphanerophyte, Zoo zoochorous, Auto autochorous. Values in the axis labels are percentages of variance explained.

and leaf nutrient content (LN, LP, LCN), correlated to the second component. Functional group 1 (B. spiciformis, B. wangermeeana, C. collinum, J. globiflora, and J. paniculata, mostly Fabaceae subfam. Caesalpinioideae) comprises ectomycorrhizal trees with large $\mathrm{H}_{\max }$ (17-22 m), mainly semi-evergreen with high LDMC, high WD and low fire tolerance (Table 1). This group displayed intermediate to high BAI $\left(15 \pm 8 \mathrm{~cm}^{2} \mathrm{y}^{-1}\right)$, high recruitment rates $(0.06 \pm 0.04)$, and represented the late-successional canopy layer. Group 2 comprised three evergreen species (M. macroura, M. katangensis, Pa. curatellifolia), with large $\mathrm{H}_{\max }(16-23 \mathrm{~m})$, WD $\left(0.68 \pm 0.06 \mathrm{~g} \mathrm{~cm}^{-3}\right)$, and BAI $\left(26 \pm 24 \mathrm{~cm}^{2} \mathrm{y}^{-1}\right.$ ), but differed from the first group by the low LA, generally low SM (mainly wind-dispersed), and the lowest recruitment and mortality rates $(0.06 \pm 0.04$ and $0.0006 \pm 0.001$, respectively; Table 1). These trait values typically correspond to a profile of conservative, stress-tolerant life strategy. Group 3 comprised six species ( $A$. antunesiana, D. boehmii, Pe. angolensis, $P$. katangensis, Pt. angolensis, $P$. tinctorius, all Fabaceae, mainly Faboideae) non-ectomycorrhizal, deciduous with high LA, LN and LP, low LCN and SM (mainly autochorous), and medium $\mathrm{H}_{\max }(13-20 \mathrm{~m})$. This group was characterized by high recruitment rates $(0.06 \pm 0.03)$ and the highest mortality rate $(0.0243 \pm 0.0203)$. Functional traits and demography point to a fastgrowing, acquisitive strategy. Finally, group 4 included five species $(D$. condylocarpon, $H$. monopetalus, $P$. maprouneifolia, $S$. innocua, $U$. nitida) mostly microphanerophytes with $\mathrm{H}_{\max }<15 \mathrm{~m}$, deciduous with high LP, low LA and WD, animal-dispersed propagules, mostly non-ectomycorrhizal and fire-resistant. This group has low BAI and presents intermediate values of recruitment and mortality rates. This corresponded to the understorey species strategy.

\subsection{Modelling tree vital rates}

As expected, individual growth (BAI) was positively influenced by initial DBH of individuals for 18 species out of 19. Other significant predictors of growth were, in decreasing order of importance: the functional dissimilarity of the neighbourhood, soil variables, and stand structure variables (Fig. 2a, Table S7). The main influencing variables were DBH (18 species out of 19; not represented in Fig. 2) followed by $\mathrm{WD}_{\mathrm{FD}}(6$ species), $\mathrm{BD}$ (associated to $\mathrm{Al}_{\mathrm{Sat}}$ ( 5 species), $\mathrm{Ca}_{\mathrm{Av}}$ (5 species), $\mathrm{FTol}_{\mathrm{FD}}$ (4), OM ( 3 species), and quadrat mean DBH ( 3 species). The individual DBH and $\mathrm{OM}$ always had a positive effect on growth, while the sign of the effect was species-dependent for the remaining above-mentioned variables. The effect of the other variables appeared for $<3$ species out of 19 .

The growth of the whole community was mainly driven by the individual's DBH (47.96), relative mortality rate (8.48), BD $(-5.96)$, quadrat mean DBH $(-3.38)$ and BA $(-3.21)$ (in brackets: values of the coefficient estimates). For all the groups, growth was negatively impacted by stand structure variables (i.e. quadrat mean DBH and quadrat total BA; Fig. 2). BD had a negative effect on growth of the functional groups 1 and 4 . Remarkably, Group 1 and 3 were both influenced by Deci $_{\mathrm{FD}}$ and $\mathrm{LP}_{\mathrm{FD}}$ but in opposite directions (negative and positive, respectively). Proportionally, Group 2 appeared to only be slightly influenced by soil or the surrounding species compared to the other groups.

946 stems were recruited from 2010 to 2014, for a total of 3370 stems of the whole non-termitophilous community, of which 871 stems belonged to the 19 species studied. J. paniculata had the largest number of recruits (393, i.e. $45 \%$ of total recruits) (Table S6). The recruitment rates were the lowest for Pe. angolensis (8.2\%), M. macroura (7.9\%), and $S$. innocua $(7.1 \%)$. At the species level, recruitment was only marginally influenced by soil variables ( 4 species out of 19 were influenced by soil and only two for more than one soil variable, Fig. 2b, Table S8). The quadrat mean basal area negatively influenced recruitment for three species. $\mathrm{Ca}_{\mathrm{Av}}$ had a positive effect for recruitment of three species, at the community level, and for groups 1 and 3. Recruitment of all groups was systematically influenced by the stand structure variables. However, in the same way as for the community and species levels, BA had a negative effect and Mean DBH a positive effect on recruitment. Recruitment of 

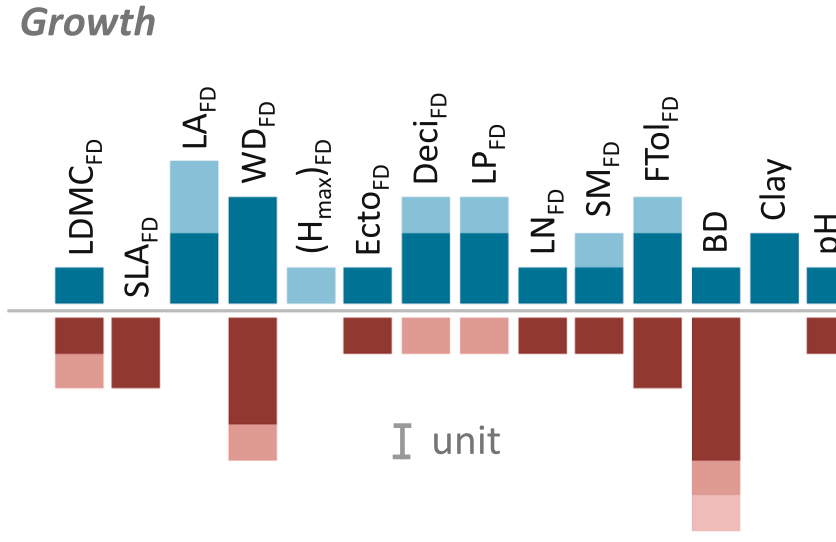

Fig. 2. Number of times each predictor was statistically significant in the multiple linear models of growth, recruitment and survival at the species, group, and community-level. Significance associated to positive and negative coefficients are in cyan and red, respectively. Each unit corresponds to the occurrence of the predictor in one of the 19 models (species level), one of the 4 model (group level) or in the single model (community level). Initial DBH influenced growth of 18 species out of 19 and was not represented in this graph. (For interpretation of the references to colour in this figure legend, the reader is referred to the web version of this article.)

\section{Survival}

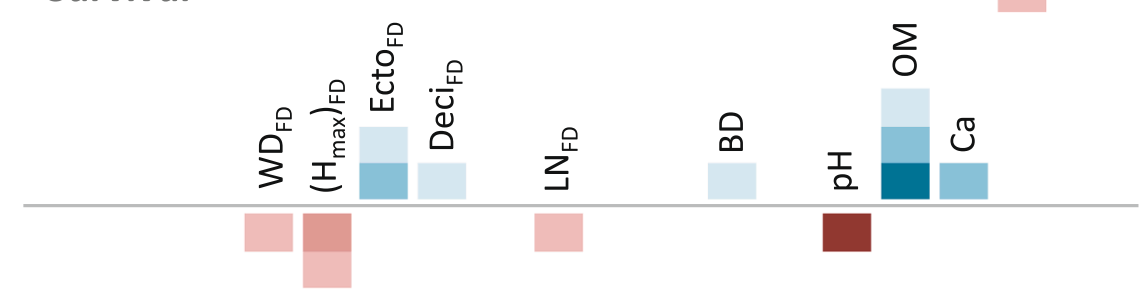

\section{Positive coefficients: \\ Species \\ Group \\ Group \\ Community \\ Community}

groups 1 and 3 was positively influenced by $\mathrm{Ca}_{\mathrm{Av}}$. Except for one value for group 2, functional dissimilarity of the surrounding individuals did not change recruitment rates at the group level.

A total of 125 individuals died between 2010 and 2014 (90 for the 19 most represented species). D. boehmii presented the highest mortality rate (21.4\%), followed by Pt. angolensis (15.3\%) and $J$. paniculata (2.0\%), whereas 5 species of the 19 had no mortality (Table S6). Survival could be modelled for very few species, due to the lack of power for such regression method with low sample size (Fig. 2c, Table S9). So, only two models including predictors have been constructed for individual species (for J. paniculata and Pt. angolensis). At the community level, functional dissimilarity (WD, $\mathrm{H}_{\text {max }}$ : negative effects; Ecto, Deci: positive effects) and soil variables (BD, OM; positive effects) influenced survival. Only group 3 could be modelled for survival. It was positively influenced by $\mathrm{BD}, \mathrm{Ca}_{\mathrm{Av}}, \mathrm{OM}$, and Ecto $\mathrm{FD}_{\text {. }}$.

The analyses showed significant correlations among demographic rates, partially supporting demographic trade-offs. In this way, a positive relation between individual recruitment and growth rate (mean plot-species-specific BAI) was observed at the community level (Table S8). A positive relation was also identified between individual growth and population mortality rate (Table S7). A negative relationship between species BAI and population recruitment rate was also confirmed $\left(r^{2}=0.15, P=0.10\right)$ as well as positive relation between individual recruitment and population mortality rate for group 3 (Table S8), in accordance with a fast-growing strategy. However, contrary to the theoretical expectations related to the stature-recruitment axis strategy (Rüger et al., 2018), we found positive relation between individual growth and the population recruitment rate in the community (Table S7).

\section{Discussion}

The general objective of this study was to identify the drivers of tree species dynamics in a miombo woodland using demographic and functional data of the 19 most frequent species. Such African dry tropical woodlands are original and poorly studied systems offering the opportunity to evaluate the importance of different coexistence mechanisms and highlight specific trade-offs in tropical tree vital rates. In this context, separating the effects of the environment (soil chemical and physical properties), stand structure, and the neighbourhood (functional dissimilarity and dominance) on demographic rates is of great relevance. 


\subsection{Relations of vital rates with soil and stand structure variables}

The influence of soil fertility on tree growth has been shown experimentally (Allen, 1986; Wright et al., 2011; Grossman et al., 2017; Cuma Mushagalusa et al., 2018), or at regional scales (e.g., Quesada et al., 2009). However, relationships of growth, recruitment, and survival rates with soil fertility have rarely been found at local scale (but see Baker et al., 2003b; Russo et al., 2005; Zemunik et al., 2018). In this study, tree growth was positively influenced by $\mathrm{Ca}_{\mathrm{Av}}$ and $\mathrm{OM}$ and negatively affected by $\mathrm{BD}$ and/or $\mathrm{Al}_{\text {Sat }}$. Structural variables (quadrat $\mathrm{BA}$ and mean $\mathrm{DBH}$ ) affected growth negatively (J. paniculata, A. antunesiana, the whole community and groups 1, 3 and 4), and always had a negative impact on recruitment ( 3 species, the whole community and all the groups). Whereas the successional stage (mirrored by the mean $\mathrm{DBH}$ ) almost always reduced growth, it was beneficial for recruitment, pointing out a positive effect of the time lapsed since the last major local disturbance. Basal area was correlated to stand density and displayed negative relations with growth and recruitment, hence reflecting competition for light or other resources (neighbourhood crowding). At the community and functional group levels, the successional stage of the quadrat had a large negative effect on growth, but a positive effect on recruitment.

At the species level, negative effects of $\mathrm{BD}$ and $\mathrm{Al}_{\text {Sat }}$ on growth of groups 1 and 4 could be explained by a trade-off between access to water (high water holding capacity and deeper soils on clay texture, which favours growth of $\mathrm{Pa}$. curatellifolia and $U$. nitida) versus higher $\mathrm{P}$ availability ( $\mathrm{P}_{\text {Olsen }}, \mathrm{P}_{\text {EDTA }}$ ) offset by potential $\mathrm{Al}$ toxicity (high $\mathrm{Al}_{\text {Sat }}$ ) in coarse sandy loam soils with lower water holding capacity (which is detrimental for growth of C. collinum, J. globiflora, J. paniculata, P. maprouneifolia, Group 1 and 4, and the whole community). Growth of species from group 2 and 3 was not affected by such habitat characteristics and seemed to tolerate water shortage and Al toxicity. Species negatively impacted for growth on coarse sandy substrate with higher $\mathrm{Al}_{\text {Sat }}$ and $\mathrm{P}$ availability present higher LDMC and lower LNP than the other species (LDMC $=41.1 \pm 1.7$ vs. $37.0 \pm 4.2$, respectively; Welch $t$-test: $P<0.01$ and LNP $=12.4 \pm 1.6$ vs $15.2 \pm 4.0$, respectively; $P<0.05)$. Likewise, groups 1 and 4 had lower LNP than species of groups 2 and 3 (LNP $=13.1 \pm 2.5$ vs $16.2 \pm 4.3$; $P=0.09$ ). In the context of woody savannas, Hodgson et al. (2011) as well as Wigley et al. (2016) showed a negative relation between LDMC and soil $\mathrm{N}$ fertility. The reverse situation occurs in our site where growth of species with high LDMC was negatively affected on coarse sandy loam soils with lower $\mathrm{N}$ but high $\mathrm{P}$ supply. The contrast of LDMC values among species could therefore rather be driven by $\mathrm{P}$ availability. Calcium availability influenced growth positively for 5 species and species of group 1. This nutrient is less available on soil with high BD and $\mathrm{Al}_{\text {Sat }}$. Among the species influenced by this trade-off, many were ectomycorrhizal ( $J$. globiflora, J. paniculata, and the large majority of group 1). This might support that ectomycorrhizal species have a particular status with respect to their nutrient supply, and particularly for P (Högberg, 1990, 1992). By contrast, growth of species from group 2 and 3 were not affected by $\mathrm{Al}_{\text {Sat }}$ and water shortage on coarse sandy loam, and could benefit from higher $\mathrm{P}$ concentration in such habitat.

Soil also influenced stem recruitment for some species. When significant, the effect of $\mathrm{Ca}_{\mathrm{Av}}$ was always positive for recruitment, including at the group level (groups 1 and 3 ) and the whole community level. Survival was explained by edaphic constraints (positive influence of $\mathrm{BD}, \mathrm{Al}_{\text {Sat }}$ and $\mathrm{OM}$ ) at the community level. This is in line with another study (Wang et al., 2012).

\subsection{Competitive hierarchy or limiting similarity?}

Overall, we identified a negative effect of the neighbourhood on individual growth resulting from the hierarchy of competitive ability. The latter was detected through a negative relation of growth with the local functional dissimilarity (FD), which reflects the competition with species showing a contrasting and dominating value of the functional trait considered in the local environment (competitive hierarchy). The growth rate of the focal individual could be reduced as a consequence of the dominant species or group of the quadrat (competitive hierarchy, Kunstler et al., 2012). This negative effect was observed for species of group 1, impacted by functional dissimilarity of neighbours for LDMC, Deci, and LP. They could be impacted by species of group 3 whose growth is precisely positively influenced by $\mathrm{Deci}_{\mathrm{FD}}$ and $\mathrm{LP}_{\mathrm{FD}}$. Competitive hierarchy also affected the growth of group 4 and other species with lower WD (B. wangermeeana, A. antunesiana, and D. condylocarpon), negatively influenced by neighbours with higher WD.

Apart from competitive interactions, the functional dissimilarity of the neighbourhood ( $\mathrm{LA}_{\mathrm{FD}}$, Ecto $\mathrm{FD}_{\mathrm{FD}}$, and $\mathrm{LP} \mathrm{PD}_{\mathrm{FD}}$ ) also had a positive effect on growth (6 species) (Fig. 2, Table S7). Functional dissimilarity therefore had a large positive effect on growth at the species, group, and community levels. This could be explained by the alleviation of intraspecific competition or shared natural enemies when other strategies were represented in the neighbourhood. By contrast, species recruitment was only weakly influenced by the functional dissimilarity of the surrounding individuals. Chen et al. (2016) showed that the neighbourhood complementarity effects were the strongest for lightdemanding species. This was verified here with group 3, characterised by an acquisitive strategy, displaying 10 positive interactions out of 13 with the functional traits of the neighbourhood.

In summary, positive demographic relationships with functional dissimilarity reflected the reduction of competitive interactions between functionally dissimilar species (for species of group 3 in particular). In contrast, functional differences had a negative effect on species with traits associated to weak competitors (e.g. low WD, low or intermediate SLA, FTol).

\subsection{Demographic trade-offs and consequences for species coexistence}

Demographic trade-offs can emerge from individual strategies of resource allocation in response to multiple axes of environmental constraints. Theoretically, these trade-offs enable predicting community assemblages and ecosystem dynamics (Easdale et al., 2007; Rüger et al., 2018).

The analysis of trait distribution in the miombo tree community allowed identifying four functional groups. Maximum height, ectomycorrhizal status and leaf traits were the major axis of niche differentiation. These groups were also separated by differences in life history traits and demographic rates, as predicted by Adler et al. (2014). The growth-survival trade-off was partially detected in this community. The fast-slow continuum separated group 3 (fast-growing but low survival rate) from group 2 (slow growing conservatives with little observed mortality). Demographic rates corresponded to the classical expectation for these two groups. As seen in the previous paragraph, the predictors for growth, recruitment and survival were different among these species with contrasting strategies. We observed a second axis separating tall species (group 1, high $\mathrm{H}_{\max }$, LDMC, and mean WD) and understorey species (group 4, low $\mathrm{H}_{\max }$, WD and LDMC), corresponding to a difference in species response to the vertical light gradient. The associated demographic trade-offs were not entirely clear. However, the expected recruitment vs. growth and recruitment vs. survival trade-offs associated to the adult stature $\left(\mathrm{H}_{\max }\right)$ - seedling recruitment axis (King et al., 2006; Rüger et al., 2018) were partially confirmed in this study. We showed a significant negative correlation between species growth and species recruitment rate and a positive relation was found between individual growth and population mortality rate at the community level. Likewise, a positive relationship was detected between individual recruitment and the population mortality rate for group 3 , as expected for a fast acquisitive strategy.

Group 4 showed intermediate values of growth as well as relatively low death and recruitment rates, compared to the other groups. Their low recruitment rate did not offset their low capacity for light 
interception, a condition for a stable coexistence with tall species (Kohyama, 1993). These species do not correspond to the classical understorey strategy. They presented some trait values associated to the understorey syndrome (low $\mathrm{H}_{\max }$, LA, LN, low mortality rate), but they can also be interpreted as drought avoidance strategy. Moreover, these species had low WD and were deciduous, in opposition to the general trend in wet and dry tropical forests understorey (Poorter et al., 2006, 2014). Furthermore, understorey species of group 4 are all fire tolerant and are also found in open landscapes (chipya habitat) as pioneer species in fire-prone environments (Lawton, 1978). On the contrary, species of group 1 are fire sensitive and cannot survive in disturbed environment. They compose the canopy trees of the dry evergreen forest (Lawton, 1978) and may have benefited from the absence of fire on the site since 2003. Thus, the decisive factor regulating the groups 1-4 trade-off could be the successional status of the species and the resistance in the face of disturbance and wildfire in particular.

In line with the Russo et al.'s (2010) study and with the very contrasting values of WD among species, the demographic rates were related to WD for growth and survival (Tables S7, S9). The neighbouring dissimilarity in foliar traits also reliably predicted growth (LDMC, SLA,

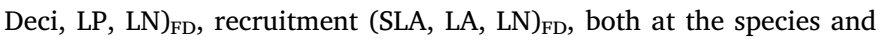
community levels, and survival (Deci $\mathrm{F}_{\mathrm{FD}}$ at the community level).

Mortality primarily affected species of the functional group 3, with a fast-growing strategy (Table S9). This higher mortality was partially compensated by higher stem recruitment compared to the other groups. Group 3 also had slow growth at this stage of the forest development, probably explained by the decreased light availability with canopy closure which was detrimental for light-demanding pioneers. This group could however strengthen in the long-term dynamic cycle after fire disturbance (Lawton, 1978; Cauldwell and Zieger, 2000).

Finally, we found a third differentiation axis which was associated to the four functional groups: Individuals with contrasting LDMC and LNP values (groups 1 and 4 vs groups 2 and 3) differed in their growth rates on soils characterised by opposed water holding capacity, Al toxicity and P fertility. This edaphic niche partitioning was not entirely comparable to the species specialisation for habitats highlighted in Muledi et al. (2017) for the same site. Soil drivers of species sorting were partly identical (P, Clay, Al, Ca), but strict species associations were rare and could not be connected to the demographic rates. Yamada et al. (2007) also showed that strong habitat specialisation in a tropical rain forest did not imply strong differences in vital rates across habitats. They suggested that contrasting performances maintaining differences in tree density may arise during exceptional climatic events. In the context of a miombo forest, this could occur after fire events.

\section{Conclusion}

Demographic data in the miombo woodlands are scarce and the functioning of this forest type ruled by light partitioning but also water and nutrient shortage is comparatively less studied than wet and moist tropical forests. A consistent set of associations has been reported between tree vital rates, soil, stand structure and functional traits. We observed distinct drivers with varying relative importance for individual growth (functional dissimilarity with the neighbourhood, soil variables and stand structure), recruitment (mainly stand structure and soil) and survival (functional dissimilarity and soil).

The interplay of tree vital rates and functional traits highlighted a competitive hierarchy related to leaf traits among the species of some functional groups, but additionally showed more numerous positive effects of the functional neighbourhood on species growth, indicating overall a stronger effect of functional complementarity. These effects were proportionally weaker on recruitment and survival.

The study highlighted different trade-offs, two of them related to functional groups defined by $\mathrm{H}_{\max }$, leaf phenology and nutrient content, ectomycorrhizal status and mean demographic rates. One trade-off involved the access to light resource $\left(\mathrm{H}_{\max }\right)$ opposed to higher recruitment and fire tolerance, the other included a conservative against an acquisitive strategy for resources, probably edaphic (LN, LP, LCN). These trade-offs are two variants of the fast-slow continuum. Another trade-off affecting growth was linked to soil variables and could lead to habitat specialisation following a gradient water vs $\mathrm{P}$ availability associated to Al toxicity. This last trade-off was mostly active on the species sorting, according to their LDMC and LNP values.

This study illustrates how the analysis of the forest community through a combination of demographic rates and functional traits allows a functional interpretation of the observed variability of vital rates among tree species and provide unique insights into the mechanisms underlying forest structuration.

\section{CRediT authorship contribution statement}

Jonathan Muledi: Investigation, Writing - original draft. David Bauman: Investigation, Methodology, Software, Formal analysis, Writing - original draft. Arnaud Jacobs: Investigation, Writing - review \& editing. Pierre Meerts: Conceptualization, Writing - review \& editing. Mylor Shutcha: Conceptualization, Supervision. Thomas Drouet: Conceptualization, Investigation, Methodology, Software, Formal analysis, Writing - original draft.

\section{Declaration of Competing Interest}

The authors declare that they have no known competing financial interests or personal relationships that could have appeared to influence the work reported in this paper.

\section{Acknowledgements}

JM was supported by the Fondation Rachel Forrest, Biodiversité au Katanga ASBL and Mikembo ASBL. This research was supported by the Belgian National Fund for Scientific Research (FRS-FNRS) aspirant research scholarship and the Wiener - Anspach Foundation for DB, and a FRIA (Fonds pour la formation à la Recherche dans l'Industrie et dans l'Agriculture) doctoral research scholarship for AJ. We thank Jean Lejoly for his contribution to the establishment of the permanent plot and all those who have contributed to the censuses, in particular E. Lowele Kalenga, P. Kizila Wimana, M. Kasongo Balonda. We gratefully acknowledge Michel Anastassiou and his family for hosting us during the field campaigns at the Mikembo Natural Reserve. We thank two anonymous reviewers for their insightful comments and helpful suggestions on an earlier version of the manuscript.

\section{Appendix A. Supplementary data}

Supplementary data to this article can be found online at https:// doi.org/10.1016/j.foreco.2020.117894.

\section{References}

Adler, P.B., Salguero-Gómez, R., Compagnoni, A., Hsu, J.S., Ray-Mukherjee, J., MbeauAche, C., Franco, M., 2014. Functional traits explain variation in plant life history strategies. Proc. Natl. Acad. Sci. U.S.A. 111, 740-745. https://doi.org/10.1073/pnas. 1315179111.

Agrawal, A.A., Fishbein, M., 2006. Plant defense syndromes. Ecology 87, S132-S149. https://doi.org/10.1890/0012-9658(2006) 87[132:PDS]2.0.CO;2.

Allen, J.C., 1986. Soil properties and fast-growing tree species in Tanzania. Forest Ecol. Manage. 16, 127-147. https://doi.org/10.1016/0378-1127(86)90014-9.

Bâ, A., Duponnois, R., Diabaté, M., Dreyfus, B., 2011. Les champignons ectomycorhiziens des arbres forestiers en Afrique de l'ouest: Méthodes d'étude, diversité, écologie, utilisation en foresterie et comestibilité. IRD Editions, Marseille.

Baker, T.R., Affum-Baffoe, K., Burslem, D., Swaine, M.D., 2002. Phenological differences in tree water use and the timing of tropical forest inventories: conclusions from patterns of dry season diameter change. Forest Ecol. Manage. 171, 261-274. https:// doi.org/10.1016/S0378-1127(01)00787-3.

Baker, T.R., Burslem, D.F.R.P., Swaine, M.D., 2003a. Associations between tree growth, soil fertility and water availability at local and regional scales in Ghanaian tropical rain forest. J. Trop. Ecol. 19, 109-125. https://doi.org/10.1017/ 
S0266467403003146.

Baker, T.R., Swaine, M.D., Burslem, D.F.R.P., 2003b. Variation in tropical forest growth rates: combined effects of functional group composition and resource availability. Perspect. Plant Ecol. 6, 21-36. https://doi.org/10.1078/1433-8319-00040.

Barot, S., Gigoux, J., 2004. Mechanisms promoting plant coexistence: can all the proposed processes be reconciled? Oikos 106, 185-192. https://doi.org/10.1111/j.0030-1299. 2004.13038.x.

Batumike, M.J., Kampunzu, A.B., Cailteux, J.L.H., 2006. Petrology and geochemistry of the Neoproterozoic Nguba and Kundelungu Groups, Katangan Supergroup, southeast Congo: implications for provenance, paleoweathering and geotectonic setting. J. Afr. Earth Sci. 44, 97-115. https://doi.org/10.1016/j.jafrearsci.2005.11.007.

Bauman, D., Raspé, O., Meerts, P., Degreef, J., Muledi, J.I., Drouet, T., 2016. Multiscale assemblage of an ectomycorrhizal fungal community: the influence of host functional traits and soil properties in a 10-ha miombo forest. FEMS Microbiol. Ecol. 92, fiw151. https://doi.org/10.1093/femsec/fiw151.

Bauman, D., Drouet, T., Dray, S., Vleminckx, J., 2018a. Disentangling good from bad practices in the selection of spatial or phylogenetic eigenvectors. Ecography 41, 1638-1649. https://doi.org/10.1111/ecog.03380.

Bauman, D., Drouet, T., Fortin, M.-J., Dray, S., 2018b. Optimizing the choice of a spatial weighting matrix in eigenvector-based methods. Ecology 99, 2159-2166. https://doi. org/10.1002/ecy.2469.

Biging, G.S., Dobbertin, M., 1995. Evaluation of competition indices in individual tree growth models. Forest Sci. 41, 360-377. https://doi.org/10.1093/forestscience/41.2. 360.

Bin, Y., Spence, J., Wu, L., Li, B., Hao, Z., Ye, W., He, F., 2016. Species-habitat associations and demographic rates of forest trees. Ecography 39, 9-16. https://doi.org/ 10.1111/ecog.00787.

Blonder, B., Moulton, D.E., Blois, J., Enquist, B.J., Graae, B.J., Macias-Fauria, M., McGill, B., Nogué, S., Ordonez, A., Sandel, B., Svenning, J.-C., 2017. Predictability in community dynamics. Ecol. Lett. 20, 293-306. https://doi.org/10.1111/ele.12736.

Borcard, D., Gillet, F., Legendre, P., 2018. Numerical Ecology with R, Second edition. Springer, pp. 435

Brenes-Arguedas, T., Ríos, M., Rivas-Torres, G., Blundo, C., Coley, P.D., Kursar, T.A., 2008. The effect of soil on the growth performance of tropical species with contrasting distributions. Oikos 117, 1453-1460. https://doi.org/10.1111/j.0030-1299. 2008.16903.x.

Brown, L., Karubian, J., 2016. Frequency-dependent selection for rare genotypes promotes genetic diversity of a tropical palm. Ecol. Lett. 19, 1439-1447. https://doi.org/ 10.1111/ele.12692.

Burnham, K.P., Anderson, D.R., 2002. Model Selection and Multimodel Inference: A Practical Information-Theoretic Approach. Springer-Verlag, New York.

Calcagno, V., de Mazancourt, C., 2010. glmulti: an R package for easy automated model selection with (generalized) linear models. J. Stat. Softw. 34, 1-29. https://doi.org/ 10.18637/jss.v034.i12.

Carstensen, B., Plummer, M., Laara, E., Hills, M., 2018. Epi: A Package for Statistical Analysis in Epidemiology. R package version 2.30. URL https://CRAN.R-project.org/ package $=$ Epi.

Cauldwell, A.E., Zieger, U., 2000. A reassessment of the fire-tolerance of some miombo woody species in the Central Province, Zambia. Afr. J. Ecol. 38, 138-146. https://doi. org/10.1046/j.1365-2028.2000.00232.x.

Chen, Y., Wright, S.J., Muller-Landau, H.C., Hubbell, S.P., Wang, Y., Yu, S., 2016. Positive effects of neighborhood complementarity on tree growth in a Neotropical forest. Ecology 97, 776-785. https://doi.org/10.1890/15-0625.1.

Chen, L., Comita, L.S., Wright, S.J., Swenson, N.G., Zimmerman, J.K., Mi, X., Hao, Z., Ye, W., Hubbell, S.P., Kress, W.J., Uriarte, M., Thompson, J., Nytch, C.J., Wang, X., Lian, J., Ma, K., 2018. Forest tree neighborhoods are structured more by negative conspecific density dependence than by interactions among closely related species. Ecography 41, 1114-1123. https://doi.org/10.1111/ecog.03389.

Comita, L.S., Uriarte, M., Thompson, J., Jonckheere, I., Canham, C.D., Zimmerman, J.K., 2009. Abiotic and biotic drivers of seedling survival in a hurricane-impacted tropical forest. J. Ecol. 97, 1346-1359. https://doi.org/10.1111/j.1365-2745.2009.01551.x.

Condit, R., Ashton, P.S., Manokaran, N., LaFrankie, J.V., Hubbell, S.P., Foster, R.B., 1999. Dynamics of the forest communities at Pasoh and Barro Colorado: comparing two 50-ha plots. Philos. T. R. Soc. B 354, 1739-1748. https://doi.org/10.1098/rstb.1999. 0517.

Condit, R., Ashton, P., Bunyavejchewin, S., Dattaraja, H.S., Davies, S., Esufali, S., Ewango, C., Foster, R., Gunatilleke, I.A.U.N., Gunatilleke, C.V.S., Hall, P., Harms, K.E., Hart, T., Hernandez, C., Hubbell, S., Itoh, A., Kiratiprayoon, S., LaFrankie, J., de Lao, S.L., Makana, J.-R., Noor, M.N.S., Kassim, A.R., Russo, S., Sukumar, R., Samper, C., Suresh, H.S., Tan, S., Thomas, S., Valencia, R., Vallejo, M., Villa, G., Zillio, T., 2006. The importance of demographic niches to tree diversity. Science 313, 98-101. https:// doi.org/10.1126/science.1124712.

Cuma Mushagalusa, F., Bauman, D., Mujinya Bazirake, B., Mleci, Y., Kalenga, M., Ngoy Shutcha, M., Meerts, P., 2018. Edaphic specialisation in relation to termite mounds in Katanga (DR. Congo): a reciprocal transplant experiment with congeneric tree species. J. Veg. Sci. 29, 921-932. https://doi.org/10.1111/jvs.12675.

Dormann, C.F., Elith, J., Bacher, S., Buchmann, C., Carl, G., Carré, G., García Marquéz, J.R., Gruber, B., Lafourcade, B., Leitão, P.J., Münkemüller, T., McClean, C., Osborne, P.E., Reineking, B., Schröder, B., Skidmore, A.K., Zurell, D., Lautenbach, S., 2013. Collinearity: a review of methods to deal with it and a simulation study evaluating their performance. Ecography 36, 27-46. https://doi.org/10.1111/j.1600-0587. 2012.07348.x.

Dray, S., Legendre, P., Peres-Neto, P., 2006. Spatial modelling: a comprehensive framework for principal coordinate analysis of neighbour matrices (PCNM). Ecol. Model. 196, 483-493. https://doi.org/10.1016/j.ecolmodel.2006.02.015.

Dray, S., Bauman, D., Blanchet, G., Borcard, D., Clappe, S., Guénard, G., ... Wagner, H.H.,
2019. adespatial: Multivariate Multiscale Spatial Analysis. R package version 0.3-4.

Easdale, T.A., Healey, J.R., Grau, H.R., Malizia, A., 2007. Tree life histories in a montane subtropical forest: species differ independently by shade-tolerance, turnover rate and substrate preference. J. Ecol. 95, 1234-1249. https://doi.org/10.1111/j.1365-2745. 2007.01290.x.

Fortunel, C., Valencia, R., Wright, S.J., Garwood, N.C., Kraft, N.J., Uriarte, M., 2016. Functional trait differences influence neighbourhood interactions in a hyperdiverse Amazonian forest. Ecol. Lett. 19, 1062-1070. https://doi.org/10.1111/ele.12642.

Franco, M., Silvertown, J., 1996. Life history variation in plants: an exploration of the fast-slow continuum hypothesis. Philos. Trans. R. Soc. B 351, 1341-1348. https://doi. org/10.1098/rstb.1996.0117.

Frost, P., 1996. Chap. 2: The ecology of miombo woodlands. In: Campbell B., Ed.), The Miombo in Transition: Woodlands and Welfare in Africa. Bogor, Indonesia: Center for International Forestry Research (CIFOR)

Gourlet-Fleury, S., Blanc, L., Picard, N., Sist, P., Dick, J., Nasi, R., Forni, E., 2005 Grouping species for predicting mixed tropical forest dynamics: looking for a strategy. Ann. For. Sci. 62, 785-796. https://doi.org/10.1051/forest:2005084.

Gourlet-Fleury, S., Houllier, F., 2000. Modeling diameter increment in a lowland ever green rain forest in French Guiana. For. Ecol. Manage. 131, 269-289. https://doi. org /10.1016/S0378-1127(99)00212-1.

Grossman, J.J., Cavender-Bares, J., Hobbie, S.E., Reich, P.B., Montgomery, R.A., 2017 Species richness and traits predict overyielding in stem growth in an early-successional tree diversity experiment. Ecology 98, 2601-2614. https://doi.org/10.1002/ ecy.1958.

Hérault, B., Bachelot, B., Poorter, L., Rossi, V., Bongers, F., Chave, J., Paine, C.E.T., Wagner, F., Baraloto, C., 2011. Functional traits shape ontogenetic growth trajec tories of rain forest tree species. J. Ecol. 99, 1431-1440. https://doi.org/10.1111/j. 1365-2745.2011.01883.x.

HilleRisLambers, J., Adler, P.B., Harpole, W.S., Levine, J.M., Mayfield, M.M., 2012. Rethinking community assembly through the lens of coexistence theory. Annu. Rev. Ecol. Evol. Sci. 43, 227-248. https://doi.org/10.1146/annurev-ecolsys-110411. 160411.

Hodgson, J.G., Montserrat-Martí, G., Charles, M., Jones, G., Wilson, P., Shipley, B., Sharafi, M., Cerabolini, B.E.L., Cornelissen, J.H.C., Band, S.R., Bogard, A., CastroDíez, P., Guerrero-Campo, J., Palmer, C., Pérez-Rontomé, M.C., Carter, G., Hynd, A., Romo-Díez, A., de Torres Espuny, L., Royo Pla, F., 2011. Is leaf dry matter content a better predictor of soil fertility than specific leaf area? Ann. Bot.-Lon. 108, 1337-1345. https://doi.org/10.1093/aob/mcr225.

Högberg, P., 1990. ${ }^{15} \mathrm{~N}$ natural abundance as a possible marker of the ectomycorrhizal habit of trees in mixed African woodlands. New Phytol. 115, 483-486. https://doi. org/10.1111/j.1469-8137.1990.tb00474.x.

Högberg, P., 1992. Root symbioses of trees in African dry tropical forests. J. Veg. Sci. 3, 393-400. https://doi.org/10.2307/3235765.

Kariuki, M., Rolfe, M., Smith, R.G.B., Vanclay, J.K., Kooyman, R.M., 2006. Diameter growth performance varies with species functional-group and habitat characteristics in subtropical rainforests. For. Ecol. Manage. 225 (1-3), 1-14. https://doi.org/10. 1016/j.foreco.2005.07.016.

King, D.A., Davies, S.J., Nur Supardi, M.N., 2006. Growth and mortality are related to adult tree size in a Malaysian mixed dipterocarp forest. For. Ecol. Manage. 223, 152-158. https://doi.org/10.1016/j.foreco.2005.10.066.

Kneitel, J.M., Chase, J.M., 2004. Trade-offs in community ecology: linking spatial scales and species coexistence. Ecol. Lett. 7, 69-80. https://doi.org/10.1046/j.1461-0248. 2003.00551.x.

Kohyama, T., 1993. Size-structured tree populations in gap dynamic forest: the forest architecture hypothesis for the stable coexistence of species. J. Ecol. 81, 131-143. https://doi.org/10.2307/2261230.

Kunstler, G., Lavergne, S., Courbaud, B., Thuiller, W., Vieilledent, G., Zimmermann, N.E., Kattge, J., Coomes, D.A., 2012. Competitive interactions between forest trees are driven by species' trait hierarchy, not phylogenetic or functional similarity: implications for forest community assembly. Ecol. Lett. 15, 831-1480. https://doi.org/ 10.1111/j.1461-0248.2012.01803.x.

Laliberté, E., Legendre, P., 2010. A distance-based framework for measuring functional diversity from multiple traits. Ecology 91, 299-305. https://doi.org/10.1890/082244.1.

Lasky, J.R., Sun, I.-F., Su, S.-H., Chen, Z.-S., Keitt, T.H., Canham, C., 2013. Trait-mediated effects of environmental filtering on tree community dynamics. J. Ecol. 101, 722-733. https://doi.org/10.1111/1365-2745.12065.

Laughlin, D.C., Strahan, R.T., Adler, P.B., Moore, M.M., 2018. Survival rates indicate that correlations between community-weighted mean traits and environments can be unreliable estimates of the adaptive value of traits. Ecol. Lett. 21, 411-421. https:// doi.org/10.1111/ele.12914.

Lawton, R.M., 1978. A study of the dynamic ecology of Zambian vegetation. J. Ecol. 66, 175-198. https://doi.org/10.2307/2259187.

Legendre, P., Legendre, L., 2012. Numerical ecology. Developments in Environmental Modelling, vol. 24 Elsevier Science BV, Amsterdam 3rd English ed.

Ledo, A., 2015. Nature and age of neighbours matter: interspecific associations among tree species exist and vary across life stages in tropical forests. PLoS One 10, e0141387. https://doi.org/10.1371/journal.pone.0141387.

Lusk, C.H., Smith, B., 1998. Life history differences and tree species coexistence in an oldgrowth New Zealand rain forest. Ecology 79, 795-806. https://doi.org/10.1890/ 0012-9658(1998) 079[0795:LHDATS]2.0.CO;2.

Maindonald, J.H., Braun, W.J., 2010. Data Analysis and Graphics Using R - An ExampleBased Approach, 3rd ed. Cambridge University Press.

McFadden, D., 1974. Conditional logit analysis of qualitative choice behavior. In: Zarembka, P. (Ed.), Frontiers in Econometrics. Academic Press, New York, pp 105-142. 
Meerts, P., 2016. An annotated checklist to the trees and shrubs of the Upper Katanga (D.R. Congo). Phytotaxa 258, 201-250. https://doi.org/10.11646/phytotaxa.258. 3.1.

Méndez-Alonzo, R., Paz, H., Zuluaga, R.C., Rosell, J.A., Olson, M.E., 2012. Coordinated evolution of leaf and stem economics in tropical dry forest trees. Ecology 93, 2397-2406. https://doi.org/10.1890/11-1213.1.

Mugasha, W.A., Eid, T., Bollandsås, O.M., Mbwambo, L., 2016. Modelling diameter growth, mortality and recruitment of trees in miombo woodlands of Tanzania. South. For. 2016, 1-14. https://doi.org/10.2989/20702620.2016.1233755.

Muledi, J.I., Bauman, D., Drouet, T., Vleminckx, J., Jacobs, A., Lejoly, J., Meerts, P., Ngoy Shutcha, M., 2017. Fine-scale habitats influence tree species assemblage in a Miombo forest. J. Plant Ecol. 10, 958-969. https://doi.org/10.1093/jpe/rtw104.

Muledi, J.I., Drouet, T., Lejoly, J., Ngongo Luhembwe, M., Shutcha, M., Meerts, P., 2018. Les dispositifs permanents du « Sanctuaire Mikembo » (Haut-Katanga), des outils pour le monitoring de la forêt claire katangaise anthropisée. In: Bogaert J., Colinet G. \& Mahy G., Anthropisation des paysages katangais. Gembloux, Belgique, Presses Universitaires de Liège - Agronomie-Gembloux. pp. 101-109.

Olano, J.M., Laskurain, N.A., Escudero, A., De La Cruz, M., 2009. Why and where do adult trees die in a young secondary temperate forest? The role of neighbourhood. Ann. For. Sci. 66, 105. https://doi.org/10.1051/forest:2008074.

Ozinga, W.A., Schaminée, J.H., Bekker, R.M., Bonn, S., Poschlod, P., Tackenberg, O., Bakker, J., van Groenendael, J.M., 2005. Predictability of plant species composition from environmental conditions is constrained by dispersal limitation. Oikos 108, 555-561. https://doi.org/10.1111/j.0030-1299.2005.13632.x.

Pakeman, R.J., Quested, H.M., 2007. Sampling plant functional traits: What proportion of the species need to be measured? Appl. Veg. Sci. 10, 91-96. https://doi.org/10.1111/ j.1654-109X.2007.tb00507.x.

Pausas, J.G., Keeley, J.E., 2014. Evolutionary ecology of resprouting and seeding in fireprone ecosystems. New Phytol. 204, 55-65. https://doi.org/10.1111/nph.12921.

Pérez-Harguindeguy, N., Díaz, S., Garnier, E., Lavorel, S., Poorter, H., Jaureguiberry, P., Bret-Harte, M.S., Cornwell, W.K., Craine, J.M., Gurvich, D.E., Urcelay, C., Veneklaas, E.J., Reich, P.B., Poorter, L., Wright, I.J., Ray, P., Enrico, L., Pausas, J.G., de Vos, A.C., Buchmann, N., Funes, G., Quétier, F., Hodgson, J.G., Thompson, K., Morgan, H.D., ter Steege, H., Sack, L., Blonder, B., Poschlod, P., Vaieretti, M.V., Conti, G., Staver, A.C., Aquino, S., Cornelissen, J.H.C., 2016. Corrigendum to: New handbook for standardised measurement of plant functional traits worldwide. Aust. J. Bot. 64 (8), 715-716. https://doi.org/10.1071/BT12225 CO.

Pinto, S.M., MacDougall, A.S., 2010. Dispersal limitation and environmental structure interact to restrict the occupation of optimal habitat. Am. Nat. 175 (6), 675-686. https://doi.org/10.1086/652467.

Poorter, L., Bongers, F., 2006. Leaf traits are good predictors of plant performance across 53 rain forest species. Ecology 87, 1733-1743. https://doi.org/10.1890/00129658(2006) 87[1733:LTAGPO]2.0.CO;2.

Poorter, L., Bongers, L., Bongers, F., 2006. Architecture of 54 moist-forest tree species: traits, trade-offs, and functional groups. Ecology 87, 1289-1301. https://doi.org/10. 1890/0012-9658(2006) 87[1289:AOMTST]2.0.CO;2.

Poorter, L., McNeil, A., Hurtado, V., Prins, H.H., Putz, F.E., 2014. Bark traits and lifehistory strategies of tropical dry- and moist forest trees. Funct. Ecol. 28, 232-242. https://doi.org/10.1111/1365-2435.12158.

Prado-Junior, J.A., Schiavini, I., Vale, V.S., Arantes, C.S., Sande, M.T., Lohbeck, M., Poorter, L., 2016. Conservative species drive biomass productivity in tropical dry forests. J. Ecol. 104, 817-827. https://doi.org/10.1111/1365-2745.12543.

Quesada, C.A., Lloyd, J., Schwarz, M., Baker, T.R., Phillips, O.L., Patiño, S., Czimczik, C., Hodnett, M.G., Herrera, R., Arneth, A., Lloyd, G., Malhi, Y., Dezzeo, N., Luizão, F.J., Santos, A.J.B., Schmerler, J., Arroyo, L., Silveira, M., Priante Filho, N., Jimenez, E.M., Paiva, R., Vieira, I., Neill, D.A., Silva, N., Peñuela, M.C., Monteagudo, A., Vásquez, R., Prieto, A., Rudas, A., Almeida, S., Higuchi, N., Lezama, A.T., López-González, G., Peacock, J., Fyllas, N.M., Alvarez Dávila, E., Erwin, T., di Fiore, A., Chao, K.J., Honorio, E., Killeen, T., Peña Cruz, A., Pitman, N., Núñez Vargas, P., Salomão, R., Terborgh, J., Ramírez, H., 2009. Regional and large-scale patterns in Amazon forest structure and function are mediated by variations in soil physical and chemical properties. Biogeosci. Discuss. 6, 3993-4057. https://doi.org/10.5194/bgd-6-39932009.

Development Core Team, R., 2018. R: A Language and Environment for Statistical Computing. R Foundation for Statistical Computing, Vienna.

Reich, P.B., 2014. The world-wide 'fast-slow' plant economics spectrum: a traits manifesto. J. Ecol. 102, 275-301. https://doi.org/10.1111/1365-2745.12211.

Rees, M., Condit, R., Crawley, M., Pacala, S., Tilman, D., 2001. Long-term studies of vegetation dynamics. Science 293, 650-655. https://doi.org/10.1126/science. 1062586.

Rüger, N., Huth, A., Hubbell, S.P., Condit, R., 2011. Determinants of mortality across a tropical lowland rainforest community. Oikos 120, 1047-1056. https://doi.org/10. 1111/j.1600-0706.2010.19021.x.

Rüger, N., Comita, L.S., Condit, R., Purves, D., Rosenbaum, B., Visser, M.D., Wright, S.J., Wirth, C., 2018. Beyond the fast-slow continuum: demographic dimensions structuring a tropical tree community. Ecol. Lett. 21, 1075-1084. https://doi.org/10. 1111/ele.12974.

Russo, S.E., Davies, S.J., King, D.A., Tan, S., 2005. Soil-related performance variation and distributions of tree species in a Bornean rain forest. J. Ecol. 93, 879-889. https:// doi.org/10.1111/j.1365-2745.2005.01030.x.

Russo, S.E., Brown, P., Tan, S., Davies, S.J., 2008. Interspecific demographic trade-offs and soil-related habitat associations of tree species along resource gradients. J. Ecol. 96, 192-203. https://doi.org/10.1111/j.1365-2745.2007.01330.x.

Russo, S.E., Jenkins, K.L., Wiser, S.K., Uriarte, M., Duncan, R.P., Coomes, D.A., 2010. Interspecific relationships among growth, mortality and xylem traits of woody species from New Zealand. Funct. Ecol. 24, 253-262. https://doi.org/10.1111/j. 1365-2435.2009.01670.x

Salguero-Gómez, R., 2017. Applications of the fast-slow continuum and reproductive strategy framework of plant life histories. New Phytol. 213, 1618-1624. https://doi. org/10.1111/nph.14289.

Salguero-Gómez, R., Violle, C., Gimenez, O., Dylan, C., 2018. Delivering the promises of trait-based approaches to the needs of demographic approaches, and vice versa. Funct. Ecol. 32, 1424-1435. https://doi.org/10.1111/1365-2435.13148.

Sánchez-Gómez, D., Zavala, M.A., van Schalkwijk, D.B., Urbieta, I.R., Valladares, F., 2008. Rank reversals in tree growth along tree size, competition and climatic gradients for four forest canopy dominant species in Central Spain. Ann. For. Sci. 65, 605. https://doi.org/10.1051/forest:2008040.

Sapijanskas, J., Paquette, A., Potvin, C., Kunert, N., Loreau, M., 2014. Tropical tree diversity enhances light capture through crown plasticity and spatial and temporal niche differences. Ecology 95, 2479-2492. https://doi.org/10.1890/13-1366.1.

Schmitz, A., 1971. La végétation de la plaine de Lubumbashi. Série scientifique n ${ }^{\circ} 113$ Institut National pour l'Etude Agronomique du Congo, Bruxelles, Belgium.

Schrodt, F., Kattge, J., Shan, H., Fazayeli, F., Karpatne, A., Banerjee, A., Reichstein, M., Bönisch, G., Díaz, S., Dickie, J., Gillison, A., Karpatne, A., Lavorel, S., Leadley, P., Wirth, C.B., Wright, I.J., Joseph Wright, S.J., Reich, P.B., 2015. BHPMF - A hierarchical Bayesian approach to gap-filling and trait prediction for macroecology and functional biogeography. Global Ecol. Biogeogr. 24, 1510-1521. https://doi.org/10. 1111/geb.12335.

Schurr, F.M., Pagel, J., Cabral, J.S., Groeneveld, J., Bykova, O., O'Hara, R.B., Hartig, F., Kissling, W.D., Linder, H.P., Midgley, G.F., Schröder, B., Singer, A., Zimmermann, N.E., 2012. How to understand species' niches and range dynamics: a demographic research agenda for biogeography. J. Biogeogr. 39, 2146-2162. https://doi:10.1111/ j.1365-2699.2012.02737.x.

Sterck, F.J., Poorter, L., Schieving, F., 2006. Leaf traits determine the growth-survival trade-off across rain forest tree species. Am. Nat. 167, 758-765. https://doi.org/10. 1086/503056.

Swaine, M.D., Lieberman, D., Hall, J.B., 1990. Structure and dynamics of a tropical dry forest in Ghana. Vegetatio 88, 31-51. https://doi.org/10.1007/BF00032601.

Swaine, M.D., Whitmore, T.C., 1988. On the definition of ecological species groups in tropical rain forests. Vegetatio 75, 81-86. https://doi.org/10.1007/BF00044629.

Trapnell, C.G., 1959. Ecological results of woodland and burning experiments in Northern Rhodisia. J. Ecol. 47 (1), 129-168. https://doi.org/10.2307/2257252.

Uriarte, M., Swenson, N.G., Chazdon, R.L., Comita, L.S., Kress, W.J., Erickson, D., ForeroMontaña, J., Zimmerman, J.K., Thompson, J., 2010. Trait similarity, shared ancestry and the structure of neighbourhood interactions in a subtropical wet forest: implications for community assembly. Ecol. Lett. 13, 1503-1514. https://doi.org/10 1111/j.1461-0248.2010.01541.x.

Violle, C., Navas, M.L., Vile, D., Kazakou, E., Fortunel, C., Hummel, I., Garnier, E., 2007. Let the concept of trait be functional!. Oikos 116, 882-892. https://doi.org/10.1111/ j.0030-1299.2007.15559.x.

Vleminckx, J., Morin-Rivat, J., Biwolé, A.B., Daïnou, K., Gillet, J.-F., Doucet, J.-L., Hardy, O.J., 2014. Soil charcoal to assess the impacts of past Human disturbances on tropical forests. PLoS One 9, e108-e121. https://doi.org/10.1371/journal.pone.0108121.

Vleminckx, J., Drouet, T., Amani, C., Lisingo, J., Lejoly, J., Hardy, O.J., 2015. Impact of fine-scale edaphic heterogeneity on trees species assembly in a central African rainforest. J. Veg. Sci. 26, 134-144. https://doi.org/10.1111/jvs.12209.

Vleminckx, J., Doucet, J.-L., Bauman, D., Hardy, O.J., Morin-Rivat, J., Biwolé, A.B., Bauman, D., Hardy, O.J., Fayolle, A., Gillet, J., Daïnou, K., Gorel, A., Drouet, T., 2017. The influence of spatially structured soil properties on tree community assemblages at a landscape scale in the tropical forests of southern Cameroon. J. Ecol. 105, 354-366. https://doi.org/10.1111/1365-2745.12707.

Wang, X., Comita, L.S., Hao, Z., Davies, S.J., Ye, J., Lin, F., Yuan, Z., 2012. Local-scale drivers of tree survival in a temperate forest. PLoS One 7, e29469. https://doi.org/10. 1371/journal.pone.0029469.

White, F., 1962. Forest flora of Northern Rhodesia. Oxford University Press, Oxford, pp. 454.

Wigley, B.J., Slingsby, J.A., Díaz, S., Bond, W.J., Fritz, H., Coetsee, C., 2016. Leaf traits of African woody savanna species across climate and soil fertility gradients: evidence for conservative versus acquisitive resource-use strategies. J. Ecol. 104, 1357-1369. https://doi.org/10.1111/1365-2745.12598.

Wright, S.J., Kitajima, K., Kraft, N.J.B., Reich, P.B., Wright, I.J., Bunker, D.E., Condit, R., Dalling, J.W., Davies, S.J., Díaz, S., Engelbrecht, B.M.J., Harms, K.E., Hubbell, S.P., Marks, C.O., Ruiz-Jaen, M.C., Salvador, C.M., Zanne, A.E., 2010. Functional traits and the growth-mortality trade-off in tropical trees. Ecology 91, 3664-3674. https://doi. org/10.1890/09-2335.1.

Wright, S.J., Yavitt, J.B., Wurzburger, N., Turner, B.L., Tanner, E.V.J., Sayer, E.J., Santiago, L.S., Kaspari, M., Hedin, L.O., Harms, K.E., Garcia, M.N., Corre, M.D., 2011 Potassium, phosphorus, or nitrogen limit root allocation, tree growth, or litter production in a lowland tropical forest. Ecology 92, 1616-1625. https://doi.org/10. 1890/10-1558.1.

Yamada, T., Zuidema, P.A., Itoh, A., Yamakura, T., Ohkubo, T., Kanzaki, M., Tan, S., Ashton, P.S., 2007. Strong habitat preference of a tropical rain forest tree does not imply large differences in population dynamics across habitats. J. Ecol. 95, 332-342. https://doi.org/10.1111/j.1365-2745.2006.01209.x.

Zambrano, J., Marchand, P., Swenson, N.G., 2017. Local neighbourhood and regional climatic contexts interact to explain tree performance. P. R. Soc. B-Biol. Sci. 284, 20170523. https://doi.org/10.1098/rspb.2017.0523.

Zemunik, G., Davies, S.J., Turner, B.L., 2018. Soil drivers of local-scale tree growth in a lowland tropical forest. Ecology 99, 2844-2852. https://doi.org/10.1002/ecy.2532. 